\title{
Postural control in children with typical development and children with profound hearing loss
}

This article was published in the following Dove Press journal:

International Journal of General Medicine

8 May 2012

Number of times this article has been viewed

\author{
Aneliza Maria Monteiro \\ de Sousa' \\ Jônatas de França Barros² \\ Brígido Martins de Sousa \\ $\mathrm{Neto}^{3}$ \\ 'Faculty of Health Sciences, University \\ of Brasilia, Brasilia, Federal District, \\ Brazil; ${ }^{2}$ Department of Physical \\ Education at the Federal University \\ of Rio Grande do Norte, Natal, Rio \\ Grande do Norte, Brazil; ${ }^{3}$ University \\ Center UNIEURO, Brasilia, Federal \\ District, Brazil
}

Correspondence: Aneliza Maria Monteiro de Sousa

SHCES Quadra 407 Bloco A

Apartamento 402, Cruzeiro

Novo, Brasília-DF, 70.650-47I

Tel +55 6 I 3879-705 I

Email anelizamonteiro@gmail.com
Purpose: To describe the behavior of the postural control in children with profound sensorineural hearing loss and compare the results of experimental tests with hearing children aged 7 to 10 years.

Patients and methods: This is a cross-sectional study where 100 children were divided into experimental and control groups. We used a force platform, AccuSway Plus, where the tests were conducted under the experimental conditions: open base, eyes open (OBEO); open base, eyes closed (OBEC); closed base, eyes open (CBEO); closed base, eyes closed (CBEC). The body sway velocity (V) of the center of pressure, the displacement in the anteroposterior direction (COPap) and mediolateral (COPml) of the center of pressure were the parameters to evaluate the postural control. For statistical analysis we used the nonparametric Mann-Whitney $U$ test, with a significance level of $5 \%$.

Results: In comparisons of variables between the groups, the experimental group outperformed by at least $75 \%$ of the control group values. In terms of global trends, the experimental group shows higher values of body oscillations in all experimental conditions and variables evaluated. Children with hearing loss had poorer balance performance compared to the group of hearing. The inferential analysis revealed a statistically significant difference in the balance between deaf and hearing children in the OBEC experimental condition in relation to the COPml parameter $(P=0.04)$. There were no statistically significant differences in comparisons between the sexes when the groups were analyzed separately. The prevalence of unknown etiology showed $58 \%$ of cases and congenital rubella in $16 \%$. The discovery of deafness occurred in $70 \%$ of children before the age of 3 years.

Conclusion: In this study, children with hearing loss had poorer balance performance compared to the group of hearing children. This finding confirms the need to investigate postural control through longitudinal studies to identify the area of sensory deficit causing poor balance performance and promote more specific early interventions.

Keywords: postural control, hearing impairment, balance, children, sensory deprivation, early intervention

\section{Introduction}

Balance is the process of maintaining the center of pressure (COP) by projection of the center of gravity on the ground within the support base of the body, which requires continuous adjustments of muscle activity and joint positioning. ${ }^{1}$ The COP is the point of application of vertical resultant forces acting on the support surface, and represents the collective result of the postural control system and the gravity force. ${ }^{1}$

Maintaining balance of the human body is a dynamic problem and its regulation depends on the combination of sensory information obtained from vestibular, 
proprioceptive, and visual systems. ${ }^{1-3}$ These receptors act in a complex, integrated, redundant and different way for each disturbance on the human body. The passive properties of the musculoskeletal system, especially the stiffness of biological structures, also play an important role in maintaining balance. $^{1}$

Situations that produce changes in the function of one of these systems may cause balance impairment. ${ }^{4}$ Because the relationship between sensory information, postural control, and motor action is complex and dynamic, many authors recommend examining this relationship through the manipulation of sensory information, and analyzing the effects on the functioning of the postural control system through the use of a force platform. ${ }^{3-5}$

The development and maintenance of postural stability is a multistep processing system that does not depend only on vestibular inputs. The maturational changes in other sensory systems (mainly visual and proprioceptive), processing of the central nervous system, and motor-coordination response are responsible for the observed changes in postural skills through adolescence. ${ }^{5}$

Several studies of motor skills in children with hearing loss observed deficits in balance, general dynamic coordination, eye coordination, and ball-catching abilities, as well as cited clear differences in reaction times and speed of movement. ${ }^{6-8}$

A study of 36 deaf children evaluated dynamic balance skills using the Körperkoordinations Test für Kinder (KTK), which assesses gross body control, and coordination. It consists of four tasks. They also evaluated static balance using the one-leg stand test. The results showed significant difference between the hearing children and the deaf children independently of the use of cochlear implants. ${ }^{9}$

Also in recent research, the motor coordination test using the KTK and the analysis of postural stability using posturography were analyzed between deaf and hearing children in Brazil. Results indicated that children with sensorineural hearing loss had poorer static balance performance when compared to hearing children of the same age and sex. These findings confirm the idea that these deaf children showed a deficit of sensory organization, which justifies the use of specific motor programs in the routine monitoring of these children. ${ }^{5,9-12}$

In general childhood, children have good balance near normal to adulthood, depending mainly on their experiences. ${ }^{13}$ When this phase of life is associated with hearing loss, there may be a long period of sensory deprivation that may reflect significant motor delay in this population.
The possible explanations of the motor deficits observed in deaf children are described in four categories: (a) organic factors, vestibular or neurological dysfunction; (b) sensory deprivation of hearing; (c) verbal language deprivation including verbal representation, lack of motor skills, verbal conceptual strategies to support implementation; (d) emotional factors such as lacking confidence because of overprotection or parental neglect. These categories can cause the deaf child to be less willing to explore the environment. ${ }^{8}$

It is known that older deaf children who have experienced long periods of auditory deprivation can be expected to demonstrate motor development later than younger deaf children with shorter periods of auditory deprivation. Fine motor control in contrast to gross motor skills tended to be obtained later when prelingual deaf children aged. ${ }^{14}$

The auditory deprivation from birth brings changes in the functional plasticity of the central nervous system. One such change is the activation of brain areas known by different sensory sources, as illustrated by the role of visual information from lip reading and sign language communication. ${ }^{15,16}$ Significant changes also occur in the plasticity of deaf patients who received a cochlear implant, as demonstrated by the hearing adaptation that occurs due to modification of peripheral frequency map and the activation of brain areas necessary for auditory processing. ${ }^{15}$

Children with hearing loss have an increased risk of deficits in balance and gross motor skills compared to children with typical development. As balance is a fundamental skill for the motor development of children, there is a need for new studies to further knowledge of the functions of sensory mechanisms in the maintenance of postural control in children with deafness.

Future scientific knowledge should help medical treatments, speech therapy, physiotherapy, and physical therapy to not only identify the sensory deficits of children with hearing impairment, but mainly to track and target future interventions and ensure a better quality of life through preventive care applied in these children.

Consequently, this research describes the behavior of COP displacement on postural control in children with sensorineural hearing loss, and compares mean values from manipulation of sensory information with that in hearing children aged 7 to 10 years.

\section{Material and methods Population and sample}

This is a cross-sectional study. Forty-three children with bilateral sensorineural hearing loss (hearing level up to or 
equal to $96 \mathrm{~dB}$ in the better ear) constituted the experimental group (EG). All were selected from the Ludovico Pavoni Hearing and Language Educational Center (CEAL) in Brasilia, Federal District, Brazil. All hearing-impaired children were in regular school classes and received intervention in the opposite turn of class period.

In the experimental group, $51 \%$ of children wore a hearing aid, and 49\% had cochlear implants (Table 1). Audiograms and other examinations were available to all children with hearing loss evaluated in this study. The intelligence quotient (IQ) test was not used in this study.

The control group (CG) was formed by 57 children with normal hearing recruited from the Institute of Education Sagarana (http://www.institutosagarana.com.br), also in the Federal District, Brazil. The hearing children participated in two extracurricular activities per week. Institutions participating in this study had similar socioeconomic profiles.

The parents or guardians of all children evaluated gave their informed consent. All children in the study were selected from both sexes and were aged between 7 and 10 years old.

\section{Procedure for data collection}

The research project was approved by the Ethics Committee on Human Research of the Faculty of Health Sciences at the University of Brasilia (UnB) n 124/2006.

Table I Characteristics of children with sensorineural hearing loss in relation to etiology, time to diagnosis, and technological auditory interventions

\begin{tabular}{ll}
\hline Variables & $\begin{array}{l}\text { Experimental group } \\
(\mathbf{n}=\mathbf{4 3})\end{array}$ \\
\hline Etiology of deafness & $\mathbf{n}(\%)$ \\
Unknown & $25(58)$ \\
Rubella & $6(16)$ \\
Genetics & $3(7)$ \\
Consanguinity & $2(5)$ \\
Cytomegalovirus & $\mathrm{I}(2)$ \\
Ear infection & $\mathrm{I}(2)$ \\
Drugs & $\mathrm{I}(2)$ \\
Meningitis & $\mathrm{I}(2)$ \\
Ototoxicity & $\mathrm{I}(2)$ \\
Waardenburg syndrome & $\mathrm{I}(2)$ \\
Toxoplasmosis & $\mathrm{I}(2)$ \\
Age of discovery of deafness & $\mathbf{n}(\%)$ \\
Congenital & $8(18)$ \\
$<3$ years & $30(70)$ \\
$>3$ years & $5(12)$ \\
Technological interventions & $\mathbf{n}(\%)$ \\
Users of hearing aids & $22(5 \mathrm{I})$ \\
Users of cochlear implants & $21(49)$ \\
\hline
\end{tabular}

The criteria applied for inclusion were: presence of bilateral profound sensorineural hearing loss (audiometric threshold greater than $96 \mathrm{~dB}$ constitutes a profound hearing loss, requirement for the experimental group); aged between 7 and 10 years; possessing the same nutritional and socioeconomic status; and have an interest in participating in the study. Exclusion criteria were: presence of any other associated disabilities (neurological, visual, or mental); classified as overweight or obese; presence of musculoskeletal problems; or using medication affecting the central nervous system.

The CEAL is a referral center for deaf care that does not include deaf with multiple associated disabilities. This guaranteed the exclusion of deficiencies associated with hearing loss. Data from the medical records were provided by skilled professionals who accompanied the children.

The experimental group was examined initially. The tests were explained orally by researchers in Brazilian sign language (LIBRAS). Hearing-impaired children were accompanied by their usual teachers for clarification of test protocols.

After the adaptation period to the test environment, the children were told they should stand barefoot as stable as possible at a suitable location for placement of the feet, with arms positioned beside the body and gaze set on one point at the level of the child's eyes on the wall $2 \mathrm{~m}$ away. The children were evaluated and the approximate time of 10 minutes was granted for familiarization with the equipment and explanations of the procedures by researchers. The equipment was calibrated individually for each child by respecting the biological individuality of each, for example, marking the base of support.

The position of the feet in a support base was freely chosen by the children. Based on the positioning of the feet, a distance equal to the width of the hip was demarcated with tape on the first try to keep the same reference in subsequent repetitions. Children were then evaluated in the control group using the same procedure described above.

To collect data from balance, the force platform AccuSway Plus (Advanced Mechanical Technology, Inc, Watertown, MA) was used, and data was interpreted with Balance Clinic software (Advanced Mechanical Technology, Inc).

Each condition made three attempts for 30 seconds, totaling 12 attempts per child, and the frequency of acquisition signal was $100 \mathrm{~Hz}$. A fourth-order low-pass filter was used to filter the data. The cutoff frequency was $10 \mathrm{~Hz} .{ }^{17}$

Although the most widely used instrument for assessing postural control is the force platform and COP is the most commonly used measure, there is no consensus in the literature about which variables should be used for COP 
assessment of postural control. ${ }^{1}$ The following stabilometric parameters were statistically analyzed: velocity of the COP, the displacement of the center of pressure in the direction anteroposterior COPap (cm) and the displacement of the center of pressure in the mediolateral direction COPml $(\mathrm{cm})$.

The record of the COP for the study of body balance was carried out with support of two feet on the force platform, in the four experimental conditions tested: open base, eyes-open (OBEO); open base, eyes-closed (OBEC); closed base, eyesopen (CBEO); closed base, eyes-closed (CBEC).

\section{Statistic treatment}

Analysis of the results was performed using descriptive statistics. Data normality was checked with the Shapiro-Wilk test, which showed that the data did not follow a normal distribution. We used the nonparametric Mann-Whitney $U$ test, which evaluates the differences between the central tendencies (means). For all tests, we used the Statistica progam (v. 7.0; StatSoft, Inc, Tulsa, OK). The level of significance for all tests was 0.05 .

\section{Results}

The study included a total of 100 children aged between 7 and 10 years old. The experimental group had 43 children (20 male, 23 female) with bilateral profound sensorineural hearing loss $(8.42 \pm 1.14$ years old $)$. The control group had 57 hearing children ( 27 male, 30 female) $(8.42 \pm 1.10$ years old) (Table 2).

The results showed no statistically significant differences in comparisons between the sexes when the groups were analyzed separately. However, other studies have shown the opposite. ${ }^{18}$

Table 1 presents the various factors associated with hearing loss in the experimental group. The prevalence of unknown etiology showed $58 \%$ of cases and congenital rubella in $16 \%$. The discovery of deafness occurred in $70 \%$ of children aged $<3$ years.

In comparisons of variables, body sway velocity (V) of the center of pressure, the displacement in the anteroposterior direction (COPap) and mediolateral (COPml) of the center

Table 2 Children distribution by groups, sex, and average age

\begin{tabular}{lll}
\hline Variables & Groups \\
\cline { 2 - 3 } & Experimental & Control \\
\hline Number of children & 43 & 57 \\
Male & 20 & 27 \\
Female & 23 & 30 \\
Age (years) & $8.42 \pm 1.14$ & $8.42 \pm 1.10$ \\
\hline
\end{tabular}

of pressure, between the groups, the experimental group outperformed by at least $75 \%$ of the control group values, which indicates a considerable difference (Table 3 ). This suggests that the experimental group in terms of global trends, shows higher values of body oscillations in all experimental conditions and variables evaluated. Therefore children with hearing loss had poorer balance performance compared to the control group. Inferential analysis revealed a statistically significant difference in balance between deaf and hearing children in the experimental condition $\mathrm{OBCE}$ in relation to the COPap parameter $(P=0.04)$. Figure 1 shows the statistically significant differences.

\section{Discussion}

In the present study, the unknown etiology of hearing loss was the most significant, with $58 \%$ of cases corroborating the studies. ${ }^{19,20}$ The prevalence of congenital rubella was found in $16 \%$ of cases and was the most significant identifiable cause of hearing impairment.

Given the significant percentage of unknown causes in this sample, we recommend the application of validated instruments for the study population, and an early intervention with objective tests against the suspected disability. It is essential for parents and professionals to be aware of the need for children to be referred early to specialist institutions

Hearing loss was discovered before the age of 3 years in $70 \%$ of children studied. In $12 \%$ of cases, the hearing loss was detected only after 3 years. All children utilized technological auditory interventions: $51 \%$ used personal sound amplification devices (hearing aids) and 49\% had a cochlear implant. The results of this study showed no statistically significant differences in comparisons between the sexes when the groups were analyzed separately, therefore the data agrees with previous studies. ${ }^{10,21,22}$

The literature shows that the physical structures of preschool children are similar, and it is almost impossible to differentiate the sexes when viewed from behind as the physical differences between the sexes are very small. ${ }^{23,24}$ Therefore, as the morphological characteristics are similar between the sexes in this phase of life, it is understood that postural control also responds in this way, ie, without the presence of statistically significant differences. Therefore, these statements are in line with the findings of this study.

Given the variability of the characteristics of children with hearing loss, and taking into account the power of the test was approximately $60 \%-65 \%$, slightly below the 
Table 3 Average results of the center of pressure parameters

\begin{tabular}{lllll}
\hline & Conditions & COPml (cm) & COPap $(\mathbf{c m})$ & $\mathbf{V}(\mathbf{c m} / \mathbf{s})$ \\
\hline Control group & OBEO & $-0.13 \pm 1.49$ & $-6.58 \pm 2.99$ & $1.32 \pm 0.31$ \\
$(\mathrm{n}=57)$ & OBEC & $-0.19 \pm 1.46$ & $-6.77 \pm 2.76$ & $1.77 \pm 0.50$ \\
& CBEO & $0.20 \pm 1.50$ & $-6.84 \pm 2.31$ & $1.90 \pm 0.45$ \\
Experimental group & CBEC & $0.24 \pm 1.68$ & $-6.67 \pm 2.39$ & $2.66 \pm 0.63$ \\
$(\mathrm{n}=43)$ & OBEO & $0.14 \pm 1.06$ & $-5.89 \pm 2.04$ & $1.31 \pm 0.33$ \\
& OBEC & $0.28 \pm 1.32$ & $-5.74 \pm 2.12$ & $1.74 \pm 0.45$ \\
& CBEO & $0.08 \pm 1.62$ & $-6.49 \pm 1.85$ & $2.09 \pm 0.50$ \\
$Z$ & CBEC & $-0.01 \pm 1.48$ & $-5.97 \pm 1.73$ & $2.95 \pm 1.09$ \\
& OBEO & -0.91 & -1.14 & 0.50 \\
& OBEC & -1.64 & -2.05 & -0.04 \\
$P$-value & CBEO & -0.04 & -1.08 & -1.71 \\
& CBEC & 0.77 & -1.62 & -0.61 \\
& OBEO & 0.36 & 0.25 & 0.62 \\
& OBEC & 0.10 & 0.04 & 0.97 \\
\end{tabular}

Notes: $Z$, value from Mann-Whitney $U$ test; $P$-value, significance level from Student's $t$-test.

Abbreviations: OBEO, open base, eyes open; OBEC, open base, eyes closed; CBEO, closed base, eyes open; CBEC, closed base, eyes closed; $\mathrm{V}$, sway velocity of the center of pressure; COPap, displacement of the center of pressure in the anteroposterior direction; COPml, displacement of the center of pressure in the mediolateral direction.

$80 \%-90 \%$ benchmark, the results obtained here should be interpreted with care as was observed in previous studies. ${ }^{5}$ We suggest that the variability of samples of children with hearing impairment be reduced to avoid challenges encountered by the majority of these investigations. An increase in experimental conditions or longer time records could avoid limitations of previous studies involving younger children. Therefore, future trials could use experimental conditions that evaluate the performance of postural control in situations that place a high demand on the systems responsible for body balance.

In the descriptive analysis, children with sensorineural hearing loss (Experimental group) had higher mean values in the variables studied in at least $75 \%$ of the experimental conditions tested when compared to hearing children. Soon, it was observed that children with sensorineural hearing loss in the CBEO experimental condition showed the following values for the parameters evaluated: COPml, $0.08 \pm 1.62 \mathrm{~cm}$;

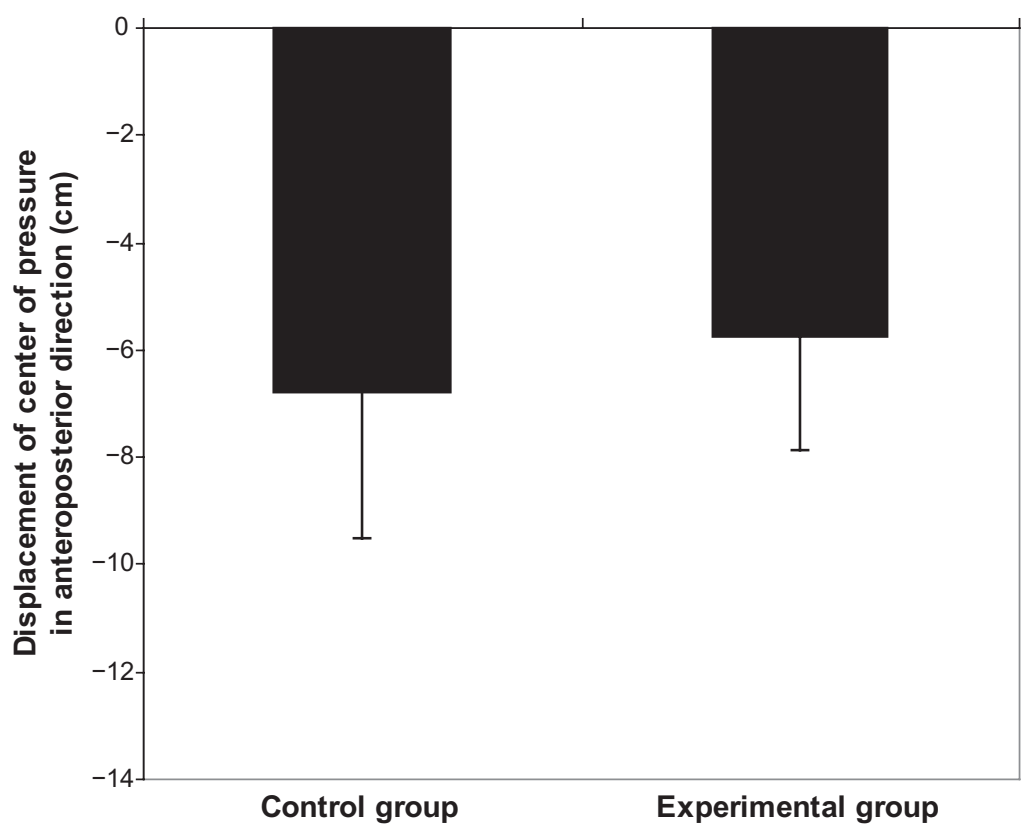

Figure I Comparison of mean values and standard deviations of variable displacement of the center of pressure in the anteroposterior direction between the control and experimental groups in the OBEC condition $(P<0.05)$. 
COPap, $-6.49 \pm 1.85 \mathrm{~cm}$; and V, $2.09 \pm 0.50 \mathrm{~cm} / \mathrm{s}$. The hearing children showed the following values under the same conditions: COPml, $0.20 \pm 1.50 \mathrm{~cm}$; COPap, $-6.84 \pm 2.31 \mathrm{~cm}$; and $\mathrm{V}, 1.90 \pm 0.45 \mathrm{~cm} / \mathrm{s}$.

Children with hearing impairment had lower static postural control compared to children of the same age and sex with typical development. These findings corroborate previous studies where children with sensorineural hearing loss demonstrated values below normal for sensory effectiveness $(P \leq 0.05) \cdot{ }^{9-11}$ These results suggest that children with sensorineural hearing loss and simultaneous vestibular dysfunction have a deficit of sensory organization that justifies the implementation of specific interventions..$^{5,10,11,22}$ It is unclear whether these differences are due to the function of the auditory nerve or other hearing loss etiologies.

In the study of inferential comparisons between groups were statistically significant differences in the OBEC experimental condition and the displacement of the COP in the anteroposterior direction: COPap, $-5.74 \pm 2.12 \mathrm{~cm}$ in the Experimental group and COPap, $-6.77 \pm 2.76 \mathrm{~cm}$ in the Control group $(P=0.04)$. There was little difference between the groups in favor of the hearing children. Thus, the group of deaf children showed less balance performance than the group of hearing children. Moreover, specifically in the CBEO experimental condition, the group of deaf children had the worst balance performance compared to the group of hearing children. This probably suggests that deaf children have learned to compensate for the deficit in postural control with other organs responsible for balance, that is, vision.

Another study also used tests of postural control in deaf children with normal and abnormal vestibular responses to evaluate the different components of sensory information in postural control. It was observed that deaf children with vestibular loss could not maintain a standing position when the visual information was removed and the somatosensory input was modified. ${ }^{5}$

Studies have shown that children with sensorineural hearing loss and concurrent vestibular dysfunction, participants of interventions with exercises, improved the sensory organization of postural control, and delayed the progressive delay in motor development. ${ }^{11,18,25}$ The identification of a deficit in sensory organization during the preintervention improves the levels of rates related to the somatosensory system and vision found in subsequent interventions, suggesting that this improvement contributes to an increased level of motor development. ${ }^{10,11}$

However, these findings of delays in motor skills and performance of postural control in deaf children are in contrast to the results reported by other studies. ${ }^{14,26} \mathrm{~A}$ possible cause of these differences in results may be differences in test instruments used (interview) and age of the children.

Recent studies have suggested that these results of atypical motor development in deaf children cannot be generalized. ${ }^{14}$ Some authors have reported in previous studies, the existence of confounding variables that could be related to the delay in motor skills in deaf children, such as differences in the types of education, presence of neurological problems, and differences in age at diagnosis of deafness and early intervention. Two studies reported motor scores of children with prelingual deafness preimplanted that were within the typical range of variation found in hearing children. ${ }^{14,26}$

When groups were compared, it was observed that the vision and support base variations were important factors in posture control. Regarding the lower performance of children with sensorineural hearing loss, it is noteworthy that the visual withdrawal of cues and manipulation of the support base further undermine the balance maintenance of these individuals. Vision becomes an important factor in controlling balance in young children. However, in the absence of visual reference, the remaining systems responsible for balance (vestibular and somatosensory) are refining their ability to respond to balance control. ${ }^{1-3}$

Due to the complexity of balance control, the diagnosis of a balance problem and its specific cause can be difficult. Maintaining balance depends on the interaction of different components, including visual, vestibular, and proprioceptive senses. From the perspective of sensory systems, young children are dependent on the visual system to maintain balance. As they age, they gradually begin to use somatosensory and vestibular information to reach full maturity by the age of 10 years. ${ }^{5}$

Postural control standards for the performance of activities of daily living improve during childhood. Physical exercise undertaken in this phase of development incorporates and automates some skills due to the stimulation of neuromuscular structures essential in postural control. ${ }^{23}$

\section{Conclusion}

Descriptive trend analysis revealed a substantial difference between the scores of the control and experimental groups because $75 \%$ of the comparisons between the groups verified the predominance of the experimental group in the statistics. Inferential Statistics showed that when there were significant differences in comparisons between groups, the experimental group always had higher scores than the control group.

Since the higher the scores, the lower the performance of postural control, children with profound sensorineural 
hearing loss had a lower performance in postural control compared to hearing children of the same age and sex.

The intrasex comparisons showed no significant differences between samples, so they were mixed in the control and experimental groups without affecting the homogeneity of the groups.

The variable displacement of the center of pressure in the anteroposterior direction, COPap, in the OBEC experimental condition was the most sensitive experimental situation for detecting differences between groups.

Therefore, these results support the idea that deaf children may have a particular sensory organization deficit, which justifies the need for access to early, more specific intervention with contributions from future longitudinal studies.

\section{Disclosure}

The authors report no conflicts of interest in this work.

\section{References}

1. Duarte M. Stabilographic Analysis of Human Upright Posture Quasi-static. Thesis presented to the University of Sao Paulo for a Contest of Free Teaching in the Area of Biomechanics; 2000. Available from http://www.teses.usp.br/teses/disponiveis/livredocencia/39/tde07022007-070941/. Accessed March 27, 2012.

2. Mochizuki L, Amadio AC. Aspectos biomecânicos da postura ereta: a relação entre o centro de massa e o centro de pressão. [Biomechanical aspects of the erect posture: the relationship between the center of mass and center of pressure]. Rev Port Cien Desp. 2003;3(3):77-83. (Brazilian).

3. Barela JA, Polastri PF, Godoi D. Postural control in children: body sway and oscillation frequency. Paulista Journal of Physical Education. 2000;14(1):68-77.

4. Prieto TE, Myklebust JB, Hoffmann RG. Measures of postural steadiness: differences between healthy young and elderly adults. IEEE Trans Biomed Eng. 1996;43(9):956-996.

5. Suarez H, Angeli S, Suarez A, Rosales B, Carrera X, Alonso R. Balance sensory organization in children with profound hearing loss and cochlear implants. Int J Pediatr Otorhinolaryngol. 2007;71(4):629-637.

6. Savelsbergh GJP, Netelenbos JB, Whiting HTA. Auditory perception and the control of spatially coordinated action of deaf and hearing impaired children. J Child Psychol Psychiatry. 1991;32(3):489-500.

7. Siegel JC, Marchetti M, Tecklin JS. Age-related balance changes in hearing-impaired children. Phys Ther. 1991;71(3):183-189.

8. Wiegersma PH, Van der Velde A. Motor development of deaf children. J Child Psychol Psychiatry. 1983;24(1):103-111.

9. Gheysen F, Loots G, Van Waelvelde H. Motor development of deaf children with and without cochlear implant. J Deaf Stud Deaf Educ. 2008;13(2):215-224.
10. Sousa AMM. Evaluation of the global motor coordination and balance in patients with hearing impairment. Master's dissertation. Brasilia, Brazil: University of Brasilia; 2006.

11. Rine RM, Braswell J, Fisher D, Joyce K, Kalar K, Shaffer M. Improvement of motor development and postural control following intervention in children with sensorineural loss and vestibular impairment. Int J Pediatr Otorhinolaryngol. 2004;68(9):1141-1148.

12. Cushing SL, Chia R, James AL, Papsin BC, Gordon KA. A test of static and dynamic balance function in children with cochlear implants: the vestibular olympics. Arch Otolaryngol Head Neck Surg. 2008;134(1):34-38.

13. Tsai CL, Wu SK, Huang CH. Static balance in children with developmental coordination disorder. Hum Mov Sci. 2008;27(1):142-153.

14. Horn DL, Pisoni DB, Sanders M, Miyamoto RT. Behavioral assessment of prelingually deaf children before cochlear implantation. Laryngoscope. 2005;115(9):1603-1611.

15. Bevilacqua MC, Martinez MAN, Balen AS, Pupo AC, Reis ACM, Frota S. Treaty of Audiology. São Paulo, Brazil: Santos; 2011

16. Bevilacqua MC, Moret ALM. Deficienncia auditiva: conversando com familiares e profissionais de saúde. [Hearing Impairment: Talking with Family Members and Health Professionals]. São José dos Campos, Brazil: Pulso Editorial; 2005;8:179-202. (Brazilian).

17. Paula MC. Comparative Analysis of the Kinematic Characteristics of the Spine During Walking and Running. Master's dissertation; 2009. UNICAMP, Campinas, SP. Available from http://www.bibliotecadigital. unicamp.br/document/?code=000440971. Accessed 2012-04-06.

18. Riach CL, Starkes JL. Velocity of centre of pressure excursions as an indicator of postural control systems in children. Gait Posture. 1994;2(3):167-172.

19. Walch C, Anderhuber W, Köle W, Berghold A. Bilateral sensorineural hearing disorders in children: etiology of deafness and evaluation of hearing tests. Int J Pediatr Otorhinolaryngol. 2000;53(1):31-38.

20. Cecatto SB, Garcia RID, Costa KS, Abdo TRT, Rezende CEB, Rapoport PB. Analysis of the main etiology of hearing loss at "Escola Especial Anne Sullivan”. Rev Bras Otorrinolaringol. 2003;69(2): 235-240.

21. Gayle GW, Pohlman RL. Comparative study of the dynamic, static, and rotary balance of deaf and hearing children. Percept Mot Skills. 1990;70(3 Pt 1):883-888.

22. Sousa A, Barros J, Sousa Neto B, Gorla J. Evaluation of the postural control and balance in children with hearing impairment. Journal of Physical Education/State University of Maringa. 2010;21(1):47-57.

23. Gallahue DL, Ozmum JC. Understanding Motor Development: Infants, Children, Adolescents and Adults. $3^{\mathrm{a}}$ ed. São Paulo, Brazil: Phorte; 2005.

24. Roman EP, Barros Filho AA. Differences on the growth and body composition between school children of German and Brazilian origin. Rev Paul Pediatr. 2007;25:(3):227-232.

25. Rival C, Ceyte H, Olivier I. Developmental changes of static standing balance in children. Neurosci Lett. 2005;376(2):133-136.

26. Kutz W, Wright C, Krull K, Manolidis S. Neuropsychological testing in the screening for cochlear implant candidacy. Laryngoscope 2003;113(4):763-766
International Journal of General Medicine

\section{Publish your work in this journal}

The International Journal of General Medicine is an international, peer-reviewed open-access journal that focuses on general and internal medicine, pathogenesis, epidemiology, diagnosis, monitoring and treatment protocols. The journal is characterized by the rapid reporting of reviews, original research and clinical studies across all disease areas.

\section{Dovepress}

A key focus is the elucidation of disease processes and management protocols resulting in improved outcomes for the patient. The manuscript management system is completely online and includes a very quick and fair peer-review system. Visit http://www.dovepress.com/ testimonials.php to read real quotes from published authors. 